\title{
Analysis of the influence of non-sinusoidal and unbalanced network modes on induction motors
}

\author{
Ngo Van Cuong ${ }^{2}$, Lidiia I. Kovernikova ${ }^{1,2^{*}}$, \\ ${ }^{1}$ Melentiev Energy Systems Institute SB RAS, Irkutsk, Russia \\ ${ }^{2}$ Irkutsk National Research Technical University, Irkutsk, Vietnam
}

\begin{abstract}
The parameters of electrical network modes do not correspond the requirements GOST 32144-2013 of Russian and the National technical regulation of Vietnam. In real operating conditions in electrical networks in non-sinusoidal and unbalanced modes there are harmonic components of voltages and currents as well as voltages and currents of negative sequence. They cause additional losses of active power, which leads to additional heating and causes premature aging of the insulation, and as the result, the reduction in the service life of induction motors. Currently, we see that the process of formation of intelligent electrical power systems is underway. Systems for continuous monitoring of power quality indices and parameters of electrical systems modes are being developed. These systems can be supplemented with programs for calculating characteristics that issue the warning when the unfavorable influence of the parameters of non-sinusoidal and unbalanced modes is detected on various electrical equipment of both electrical power systems and consumers of electrical energy. The paper provides an overview of the characteristics used to analyze, assess and predict the influence of poor power quality associated with non-sinusoidal and unbalanced of currents and voltages on induction motors. A computer program was developed to calculate these characteristics. The program was used to study the influence of non-sinusoidal and unbalanced modes on the induction motors of the coal sorting plant of the Vietnamese company "Cua Ong-Vinacomin".
\end{abstract}

\section{Introduction}

The study of the influence of the parameters of nonsinusoidal and unbalanced modes on induction motors has been engaged in for a long time, since induction motors are the most used electrical equipment [1-11]. A special standard specifies the operating conditions for induction motors with unbalanced voltages [12]. They continue to fail due to damage despite many years of ongoing research on the influence of poor power quality on induction motors. For example, in April 2017, due to the poor power quality the induction motor failed at the "Alexandrovsky Mine" enrichment plant in the TransBaikal Territory [13]. Another 17 induction motors failed at water supply facilities and in the boiler house in the Trans-Baikal Territory in December 2017 [14]. Nonsinusoidal and unbalanced modes occur very often in electrical networks in Russia [15]. Poor power quality exists in coal mining areas in Vietnam [16]. This paper provides the overview of the characteristics used in special works to analyze, assess and predict the influence of poor power quality associated with non-sinusoidal and unbalanced of currents and voltages on induction motors. The computer program "Predicting the influence of nonsinusoidal unbalanced voltage on an induction motor" based on Microsoft Excel and Matlab was developed to calculate these characteristics. The program was used to study the influence of non-sinusoidal and unbalanced voltages on induction motors of the coal sorting plant of the Vietnamese company "Cua Ong-Vinacomin". At present, intelligent electrical power systems are being created equipped with systems for continuous monitoring of mode parameters and power quality indices. They can be supplemented with programs for calculating characteristics that signal the influence of non-sinusoidal and unbalanced voltages and currents on the electrical equipment of electrical power systems and consumers of electrical energy.

\section{Additional losses of active power in the induction motor in non-sinusoidal and unbalanced network modes}

Non-sinusoidal and unbalanced voltages applied to the stator winding of the induction motor cause nonsinusoidal and unbalanced currents in the motor windings. They cause additional losses of active power. Fig. 1 presents the diagram of additional active power losses at non-sinusoidal and unbalanced voltages in the motor.

\section{Assessment of the influence of non- sinusoidal voltage on the induction motor}

The non-sinusoidal voltage leads to the increase in the active resistance to harmonic currents since at increased

* Corresponding author: kovernikova@isem.irk.ru 


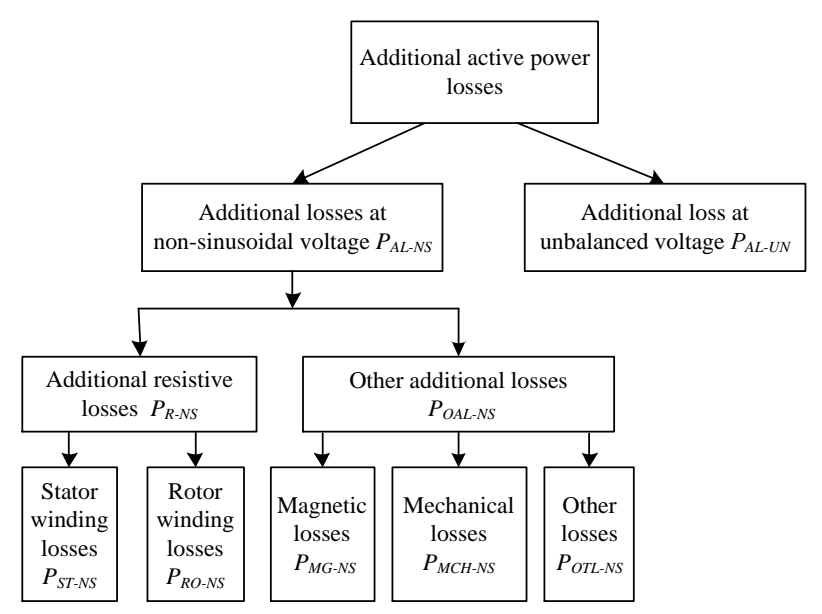

Fig. 1. Classification of active power losses in induction motor.

frequencies a skin effect appears in the stator and rotor windings. As a result, additional losses of active power appear in the induction motor, which cause heating. Additional losses at non-sinusoidal voltage consist of additional losses in the stator $\left(P_{S T-N S}\right)$ and rotor $\left(P_{R O-N S}\right)$ windings, which form additional resistive losses $\left(P_{R-N S}\right)$. Other additional losses $\left(P_{O A L-N S}\right)$ also occur in the induction motor with non-sinusoidal voltage, which are divided into magnetic $\left(P_{M G-N S}\right)$, mechanical $\left(P_{M C H-N S}\right)$ and other $\left(P_{\text {OTL-NS }}\right)$. Magnetic losses are losses in the steel of the stator and rotor for hysteresis and eddy currents arising from magnetization reversal. Mechanical losses are friction losses in bearings and friction of the rotor against air. Mechanical losses are neglected as they have little influence on motor heating. There are also additional losses that are caused by the action of harmonics of magnetomotive forces, pulsation of magnetic induction in the teeth. These additional losses are taken equal to $1 \%$ of the rated power, are taken into account and added to the losses in the rotor winding [3].

Additional resistive losses $\left(P_{R-N S}\right)$ are calculated according to $[2,4,6]$ as

$$
P_{R-N S}=K_{R} \sum_{n=2}^{50}\left[\left(K_{U(n)} \gamma\right)^{2}\left(\sqrt{n} R_{S T-S}+\sqrt{n-1} R_{R O-S}\right)\right] \text {, }
$$

where $K_{R}$ - the resistive loss coefficient in sinusoidal mode. The resistive loss coefficient is calculated by the expression

$$
K_{R}=P_{R-S} U_{1}^{2} /\left(U_{N}^{2} Z^{2}\left(R_{S T-S}+R_{R O-S}\right)\right),
$$

where

$$
Z=\frac{\sqrt{\left(X_{S T-S}+X_{R O-S}\right)^{2}}}{\sqrt{\left(R_{S T-S}+R_{R O-S} / s_{N}\right)^{2}+\left(X_{S T-S}+X_{R O-S}\right)^{2}}} \text {, p.u.; }
$$

$P_{R-S}$ - the resistive losses in the windings of both the stator and the rotor of the induction motor in sinusoidal mode, which are calculated according to [17]; $U_{l}$ - the phase voltage of the fundamental frequency; $U_{N}$ - the rated voltage; $P_{S T-S}, P_{R O-S}$ - resistances of the stator and rotor windings in sinusoidal mode, Ohm; $X_{S T-S}, X_{R O-S}$ inductances of stator and rotor windings in sinusoidal mode, Ohm.
Other additional losses $\left(P_{O A L-N S}\right)$ are determined by the expression from $[2,4,6]$ as

$$
P_{O A L-N S}=P_{R-S} U_{1}^{2} /\left(U_{1} / U_{N}\right)^{2} \sum_{n=2}^{50}\left[\left(K_{U(n)} / 100\right)^{2} n^{-0.6}\right] \text {. }
$$

Total additional losses in non-sinusoidal mode

$$
P_{A L-N S}=P_{R-N S}+P_{O A L-N S} \text {. }
$$

The actual service life of the induction motor, i.e. the service life at non-sinusoidal voltage $\left(T_{A S L-N S}\right)$ is calculated as

$$
T_{A S L-N S}=T_{S S L} e^{-(E / K) \Delta T_{N S} / T_{2}\left(T_{2}+\Delta T_{N S}\right)},
$$

where $E$ - the activation energy equal to $1.7622 \cdot 10^{-19} \mathrm{~J}$; $K$ - the Boltzmann constant equal to $1.38 \cdot 10^{-23} \mathrm{~J} / \mathrm{K}$; $T_{2}=\left(\Delta T_{N}+T_{a m b}\right)+273-$ the rated temperature of the hottest point of the motor, $\mathrm{K} ; \Delta T_{N}-$ the standard temperature rise of the winding over the ambient temperature, ${ }^{\circ} \mathrm{C} ; T_{a m b}-$ the ambient temperature, ${ }^{\circ} \mathrm{C}$. The additional temperature rise of the induction motor over the ambient temperature $\left(\Delta T_{N S}\right)$ in non-sinusoidal mode is calculated as

$$
\Delta T_{N S} \approx \Delta T_{N} P_{A L-N S} / P_{S},
$$

where $P_{S}=P_{1}-P_{N}=P_{R-S}+P_{O A L-S}-$ the total losses of the induction motor in sinusoidal mode; $P_{1}-$ power consumption at the induction motor input, which is defined as $P_{1}=P_{N} / \eta_{N}$ [17]; $P_{N}-$ the rated power of the motor (net power at the output of the motor); $\eta_{N}-$ the efficiency at rated power mode.

Efficiency of the induction motor in non-sinusoidal mode

$$
\eta_{N S}=P_{N} /\left(P_{1}+P_{A L-N S}\right) \text {. }
$$

Change in efficiency caused by non-sinusoidal voltage

$$
\Delta \eta=\eta_{N}-\eta_{N S} \text {. }
$$

\section{Assessment of the influence of unbalanced voltage on the induction motor}

In $[1,3,5]$ it is noted that the resistance of the negative sequence of induction motors is 5-8 times less than the resistance of the positive sequence. Therefore, the voltage unbalance of $1 \%$ already creates the unbalance of currents in the windings of $7-9 \%$. It is also indicated that at the value of the negative sequence voltage equal to $4 \%$ of the nominal, the service life of the induction motor is halved. When negative sequence currents flow, additional active power losses occur. Negative sequence currents cause additional heating, reduce the useful torque and available power of the induction motor. To assess the influence of unbalanced voltage on the induction motor, the parameters presented below are used.

When calculating additional active power losses $\left[P_{A L-U B}\right]$ in unbalanced mode, it is assumed that they are proportional to the losses in the stator winding at the rated current of the fundamental frequency and do not depend on the motor load [3]. Additional power losses are determined by the expression

$$
P_{A L-U B}=2.41 P_{S T-S} K_{I L}^{2} K_{2 U}^{2},
$$


where $P_{S T-S}$ - the active power losses in the stator winding in symmetrical mode at the rated current of the fundamental frequency; $K_{I L}$ - the locked-rotor current ratio at rated voltage; $K_{2 U}$ - the negative sequence voltage unbalance coefficient.

Losses of active power in the stator winding at nominal conditions are determined in [17] as

$$
P_{S T-S}=3 I_{N}^{2} R_{S T-S},
$$

where $I_{N}$ - the rated phase current of the stator of the motor; $R_{S T-S}$ - the resistance of the stator at rated power mode.

The real service life of the induction motor in unbalanced mode is defined in [3] as

$$
T_{A S L-U N}=T_{S S L} / e^{\Delta T_{U B}},
$$

where $T_{S S L}-$ the standard service life, years; $\Delta T_{U B}-$ temperature rise of induction motor windings in unbalanced mode, ${ }^{\circ} \mathrm{C} ; b$ - the coefficient characterizing the insulation of the induction motor $[18],{ }^{\circ} \mathrm{C}^{-1}$. The temperature rise of the windings in unbalanced mode is defined in [3] as

$$
\Delta T_{U B}=434 K_{2 U}^{2} / b
$$

Efficiency in unbalanced mode is

$$
\eta_{U B}=\frac{P_{N}}{P_{1}+P_{A L-U B}},
$$

where $P_{A L-U B}$ - the additional losses in the induction motor in unbalanced mode.

Change in the coefficient of efficiency caused by unbalanced voltage

$$
\Delta \eta=\eta_{N}-\eta_{U B}
$$

The above characteristics are calculated using the computer program and are presented below.

\section{The results of the analysis of the measured indices of the power quality in the power supply system of the coal sorting plant of the company "Cua Ong- Vinacomin"}

Below are the results of measurements of indices of the power quality associated with non-sinusoidal and unbalanced modes, which affect the operation of induction motors. Tables 1-3 present the results of the analysis of the measured total harmonic distortion $\left(K_{U}\right)$, the indices of the $n$-th harmonic component of the voltage $\left(K_{U(n)}\right)$, the indices of the $n$-th harmonic component of the current $\left(K_{I(n)}\right)$, the negative sequence voltage unbalance index $\left(K_{2 U}\right)$. The standard values for the indices are set at $[19,20]$. The value of the measured $\left.K_{U(n)}\right)$ should not exceed $3 \%$, and $K_{I(n)} 12 \%$. Values that do not meet regulatory requirements are shown in bold in the tables. It can be seen from the tables that the voltage is nonsinusoidal at the node for connecting the electrical network of the plant to the supply network, since $K_{U}$ is more than two times higher than the standard value. The indeces $K_{U(n)}$ and $K_{I(n)}$ are also significant. The $K_{2 U}$ value is much less than the standard value, therefore the voltage unbalance is insignificant.
Table 1. Measured $K_{U}, K_{2 U}$, and their standard values.

\begin{tabular}{|l|c|c|c|}
\hline Parameter & Phase A & Phase B & Phase C \\
\hline$K_{\text {Umax }}, \%$ & $\mathbf{1 6 , 8}$ & $\mathbf{1 5 , 3}$ & $\mathbf{1 7 , 1}$ \\
\hline$K_{\text {Ustand }}, \%$ & \multicolumn{3}{|c|}{$\leq 6,5$} \\
\hline$K_{2 \text { Umax }}, \%$ & \multicolumn{3}{|c|}{0.44} \\
\hline$K_{2 \text { Ustand }} \%$ & \multicolumn{3}{|c}{5.0} \\
\hline
\end{tabular}

Table 2. Measured $K_{U(n) \max }, \%$.

\begin{tabular}{|c|c|c|c|}
\hline$n$ & $K_{U(n) \max A}$ & $K_{U(n) \max B}$ & $K_{U(n) \max B}$ \\
\hline 3 & 2.5 & $\mathbf{3 . 9}$ & 2.0 \\
\hline 5 & $\mathbf{1 2 . 7}$ & $\mathbf{1 2 . 3}$ & $\mathbf{1 2 . 3}$ \\
\hline 7 & $\mathbf{1 2 . 8}$ & $\mathbf{1 1 . 8}$ & $\mathbf{1 2 . 8}$ \\
\hline 9 & 1.9 & 2.8 & $\mathbf{3 . 3}$ \\
\hline 11 & $\mathbf{4 . 6}$ & $\mathbf{4 . 6}$ & $\mathbf{3 . 6}$ \\
\hline 13 & 2.1 & $\mathbf{3 . 1}$ & 2.8 \\
\hline 17 & $\mathbf{3 . 3}$ & 2.7 & $\mathbf{3 . 4}$ \\
\hline 23 & $\mathbf{3 . 1}$ & 2.8 & $\mathbf{3 . 4}$ \\
\hline
\end{tabular}

Table 3. Measured $K_{I(n) \max }, \%$.

\begin{tabular}{|c|c|c|c|}
\hline$n$ & $K_{I(n) \max A}$ & $K_{I(n) \max B}$ & $K_{I(n) \max C}$ \\
\hline 3 & 7.1 & 3.9 & 3.6 \\
\hline 5 & 6.8 & 4.2 & 4.9 \\
\hline 7 & 6.7 & 1.7 & 3.3 \\
\hline 9 & 2.9 & 1.5 & 1.6 \\
\hline 11 & 3.9 & 0.8 & 1.2 \\
\hline 13 & 1.9 & 1.1 & 1.7 \\
\hline 17 & 2.3 & 0.5 & 1.5 \\
\hline 23 & 2.7 & 0.2 & 0.6 \\
\hline
\end{tabular}

\section{Prediction of the influence of non- sinusoidal and unbalance voltages on induction motors of the coal sorting plant}

At the coal sorting plant, 58 induction motors with a capacity from 4 to $185 \mathrm{~kW}$ are in operation. As an example, 2 induction motors with the power of 45 and $110 \mathrm{~kW}$ are taken for calculation. Table 4 presents their technical characteristics [21].

Table 4. Technical characteristics of induction motors.

\begin{tabular}{|l|c|c|}
\hline \multirow{2}{*}{ Parameter } & \multicolumn{2}{|c|}{ Motor type } \\
\cline { 2 - 3 } & $3 \mathrm{~K} 280 \mathrm{Sc} 8$ & $3 \mathrm{~K} 315 \mathrm{~S} 4$ \\
\hline$P_{N}, \mathrm{~kW}$ & 45 & 110 \\
\hline$U_{N}, \mathrm{~V}$ & 220 & 220 \\
\hline$\eta_{N}, \%$ & 92 & 91 \\
\hline$S_{N}$, p.u. & 0.014 & 0.023 \\
\hline$b, 1 /{ }^{\circ} \mathrm{C}$ & 0.052 & 0.052 \\
\hline$K_{I L}$, p.u. & 5.0 & 7.0 \\
\hline$R_{S T-S, \text { p.u. }}$ & 0.047 & 0.023 \\
\hline$X_{S T-S, \text { p.u. }}^{\prime}$ & 0.110 & 0.122 \\
\hline$R_{R O-S}^{\prime}$, p.u. & 0.017 & 0.019 \\
\hline$X^{\prime}{ }_{R O-S}$, p.u. & 0.12 & 0.16 \\
\hline$T_{S S L}$, years & 20 & 20 \\
\hline
\end{tabular}


The table shows: $P_{N}, U_{N}, \eta_{N}, s_{N}-$ the rated power, the voltage, the efficiency, the slip; $b$ - the coefficient characterizing the insulation of the induction motor; $K_{I L}-$ the locked-rotor current ratio at rated voltage; $R_{S T-S,}^{\prime} X_{S T-S}^{\prime}-$ the resistance and the inductance of the stator winding; $R_{R O-S}^{\prime}, X_{R O-S}^{\prime}$ - the resistance and the inductance of the rotor winding; $T_{S S L}$ - the standard service life of the motor.

The calculation of characteristics that assess the influence of non-sinusoidal and unbalanced voltages on the induction motor was carried out using the program "Predicting the influence of non-sinusoidal unbalanced voltages on an induction motor". The screenshot of Sheet 1 of the program, which shows the modules of the program, is shown in Fig. 2.

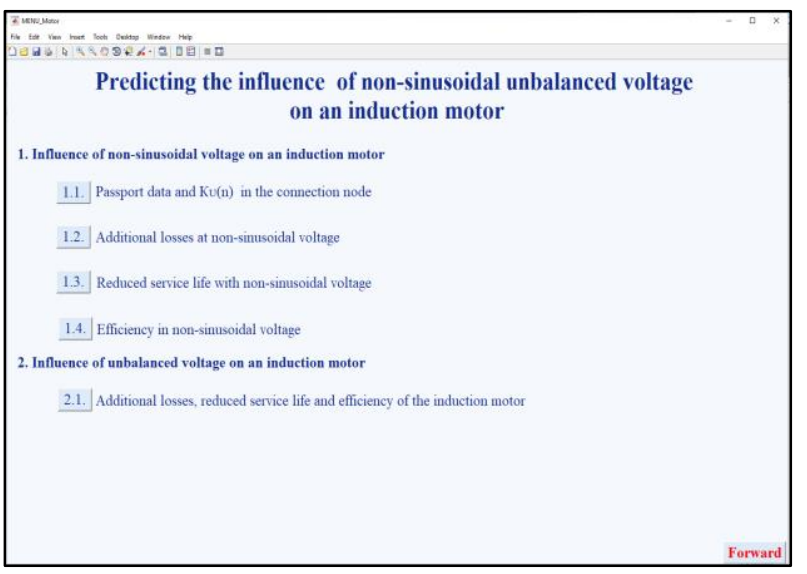

Fig. 2. Sheet 1 of the program.

Table 5 shows the characteristics that assess the influence of non-sinusoidal voltage on induction motors. The calculation results show that with the constant operation of the induction motor with a power of $45 \mathrm{~kW}$ at a nonsinusoidal voltage with the indices given in tables the actual service life can be reduced by almost 9 years. The service life of a $110 \mathrm{~kW}$ motor can be shortened by more than 3 years. The screenshot of the program showing the calculating the reduction in the service life of the induction motor with the power of $110 \mathrm{~kW}$ is shown in Fig. 3.

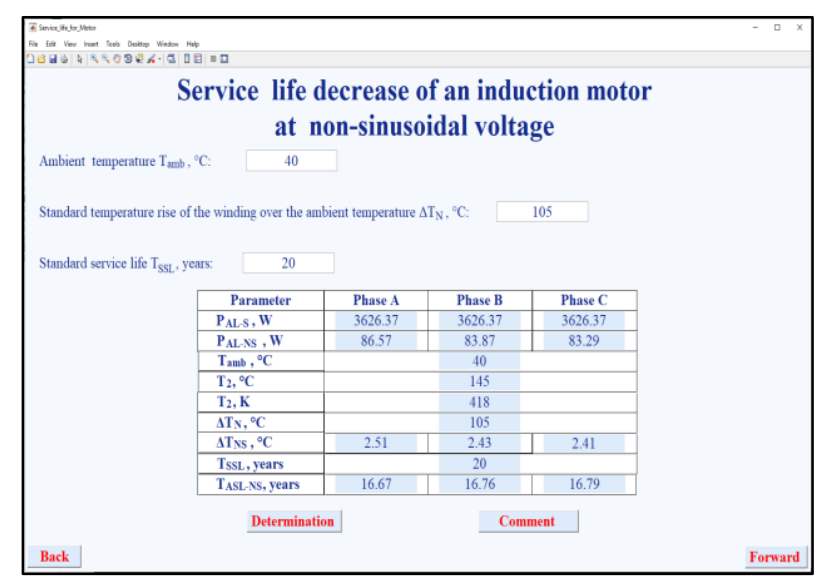

Fig. 3. Sheet of the program for calculating the service life decrease of the induction motor.
Table 5. Calculated characteristics at non-sinusoidal voltage.

\begin{tabular}{|l|c|c|c|c|c|}
\hline Motor type & $\begin{array}{c}P_{N}, \\
\mathrm{~kW}\end{array}$ & $\begin{array}{c}K_{U(n)}, \\
\%\end{array}$ & $\begin{array}{c}H_{N S}, \\
\%\end{array}$ & $\begin{array}{c}\Delta \eta, \\
\%\end{array}$ \\
\hline 3K280Sc8 & 45 & Table 2 & 91.47 & 0.53 \\
\hline 3K315S4 & 110 & Table 2 & 90.81 & 0.19 \\
\hline \multirow{2}{*}{ Motor type } & $\begin{array}{c}P_{R-N S}, \\
\mathrm{~W}\end{array}$ & $\begin{array}{c}P_{\text {OAL-NS }}, \\
\mathrm{W}\end{array}$ & $\begin{array}{c}P_{A L-N S}, \\
\mathrm{~W}\end{array}$ & $\begin{array}{c}T_{A S L}, \\
\text { years }\end{array}$ \\
\hline \multirow{3}{*}{ 3K280Sc8 } & $\mathrm{A}$ & 94.4 & 3.2 & 97.7 & 11.38 \\
\cline { 2 - 6 } & $\mathrm{B}$ & 91.7 & 3.1 & 94.8 & 11.56 \\
\cline { 2 - 6 } & $\mathrm{C}$ & 90.2 & 3.1 & 93.3 & 11.66 \\
\hline \multirow{3}{*}{ 3K315S4 } & $\mathrm{A}$ & 58.6 & 28.0 & 86.6 & 16.67 \\
\cline { 2 - 6 } & $\mathrm{B}$ & 56.9 & 27.0 & 83.9 & 16.76 \\
\cline { 2 - 6 } & $\mathrm{C}$ & 56.0 & 27.3 & 83.3 & 16.79 \\
\hline
\end{tabular}

The screenshot of the program sheet, which presents the results of calculating the characteristics that assess the influence of unbalanced voltage on the induction motor with a power of $110 \mathrm{~kW}$, is shown in Fig. 4. The calculated characteristics for two motors are given in Table 6 . The calculation results show that since the voltage unbalance is negligible, the potential reduction in service life of induction motors is less than one year.

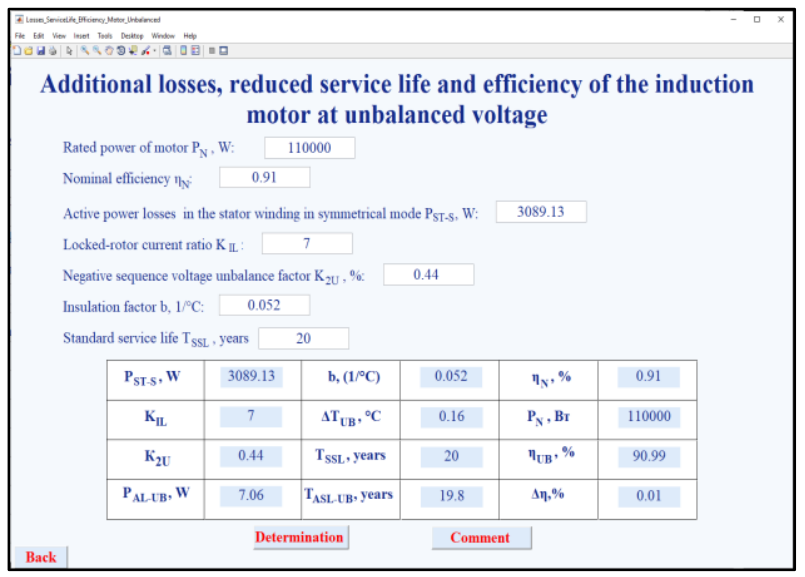

Fig. 4. Sheet of the program for calculating the characteristics of influence of unbalanced voltage on the induction motor.

Table 6. Calculated characteristics at unbalanced voltage.

\begin{tabular}{|c|c|c|c|c|}
\hline Motor type & $\begin{array}{c}P_{N}, \\
\mathrm{~kW}\end{array}$ & $\begin{array}{c}K_{2 U}, \\
\%\end{array}$ & $\begin{array}{c}P_{S T-S}, \\
\mathrm{~W}\end{array}$ & $\begin{array}{c}P_{\Sigma-U N}, \\
\mathrm{~W}\end{array}$ \\
\hline 3K280Sc8 & 45 & 0.44 & 2673.15 & 3.12 \\
\hline 3K315S4 & 110 & 0.44 & 3089.30 & 7.06 \\
\hline Motor type & $\begin{array}{c}\Delta T_{U N}, \\
{ }^{\circ} \mathrm{C}\end{array}$ & $\begin{array}{c}T_{A S L}, \\
\text { years }\end{array}$ & $\begin{array}{c}\eta_{U N}, \\
\%\end{array}$ & $\begin{array}{c}\Delta \eta, \\
\%\end{array}$ \\
\hline 3K280Sc8 & 0.16 & 19.8 & 90.99 & 0.01 \\
\hline 3K315S4 & 0.16 & 19.8 & 91.99 & 0.01 \\
\hline
\end{tabular}

\section{Conclusion}

The calculation results show that non-sinusoidal and unbalanced voltages reduce the service life of induction motors. Their premature failure will lead to economic damage. Currently, the process of formation of intelligent electrical power systems is underway. Systems for continuous monitoring of indices of the power quality and parameters of the mode of electrical networks are being 
developed. They could be supplemented with programs for calculating characteristics that predict the influence of non-sinusoidal and unbalance modes on various electrical equipment, which would facilitate a prompt response to negative changes in the parameters in order to provide reliable, high quality, cost-effective power supply to consumers.

The research was carried out under State Assignment Project (No. FWEU-2021-0001) of the Fundamental Research Program of Russian Federation 2021-2030.

\section{References}

1. A.L. Tserazov, N.I. Yakimenko, Research on the influence of voltage imbalance and non-sinusoidality on the operation of indaction motors, Information materials No. 70, (State Energy Publishing House. Moscow. Leningrad, 1963).

2. Fuchs E.F., Chang L.H., Appelbaum J., Magnetizing current, iron losses and forces of three-phase induction machines at sinusoidal and nonsinusoidal terminal voltages, IEEE Transaction on Power Apparatus and Systems, Vol. 103, No. 11, (1984).

3. A.N. Shidlovsky, V.G. Kuznetsov, Improving the power quality in electrical networks, $-\mathrm{K}$.: Naukova dumka, (1985).

4. E.F. Fuchs, D.J. Roesler, K.P. Kovacs, Aging of electrical appliances due to voltage harmonics of the power system, IEEE Transactions on Power Delivery, Vol. 1, No. 3, (1986).

5. I.V. Zhezhelenko, Yu.L. Saenko, T.K. Baranenko, A.V. Gorpinich, V.V. Nesterovich, Selected issues of nonsinusoidal modes in electrical networks of enterprises / Ed. I.V. Zhezhelenko. - M .: Energoatomizdat, (2007).

6. E.F. Fuchs, Mohammad A.S. Masoum, Power Quality in Power Systems and Electrical Machines, 2nd Edition, Elsevier, (2015).

7. Enrique C. Quispe, Ivan D. Lopez, Fernando J.T.E. Ferreira, Vladimir Sousa, Unbalanced voltages impacts on the energy performance of induction motors, IJECE Vol. 8, No. 3, (2018).

8. Sunil Singh, Ajay Srivastava, Voltage unbalance and its impact on the performance of three-phase induction motor: a review, IJRASET, Vol. 7, Issue VII, (2019).

9. Shivam Chauhan, Shashi Bhusan Singh, Effects of voltage unbalance and harmonics on 3-phase induction motor during the condition of undervoltage and overvoltage, Proc. of 6-th International Conference on Signal Processing and Integrated Networks, (2019).
10. Silvio Xavier Duarte, Nelson Kagan, Senior Member, A Power-Quality Index to Assess the Impact of Voltage Harmonic Distortions and Un-balance to Three-Phase Induction Motors, IEEE Transactions On Power Delivery, Vol. 25, No. 3, (2010).

11. Sorin Deleanu, Mihai Iordache, Marilena Stanculescu, Dragos Niculae. The Induction Machine Operating from a Voltage Supply Unbalanced and Polluted with Harmonics: A Practical Approach, 15th International Conference on Engineering of Modern Electrical Systems (EMES), Oradea, Romania, (2019).

12. GOST IEC 60034-26-2015. Rotating electrical machines. Part 26. Effects of unbalanced voltages on the performance of three-phase cage induction motors, (2017).

13. O.V. Zapanov, L.I. Kovernikova, On the quality of electrical energy supplied to the Alexandrovsky Mine Joint Stock Company. International conference "Energy of the XXI century: sustainable development and intelligent management", Irkutsk, September 7-11, (2020). URL: https://drive. google.com/file/d /12vDop Hm0i8prfjOAahahc20isxye Eqiw/view? usp =sharing.

14. Zabaikalsky Rabochy newpaper "Emergency state was introduced in the Mogochinsky district due to failure of 17 motors and the pump in boiler rooms", http: //zabrabochy.rf/news/189133/.

15. L.I. Kovernikova, V.V. Sudnova, R.G. Shamonov et al. Power quality: current state, problems and proposals for solving them (Nauka, 2017).

16. N.H. Bui, L.I. Kovernikova, Analysis of the possibility of application of active filters to reduce the non-sinusoidal voltage in the power supply system of one of the coal quarries of Vietnam, Vestnik Irkutskogo gosudarstvennogo tekhnicheskogo universiteta, Vol. 24, No. 2, (2020).

17. A.V. Ivanov-Smolensky. Electrical machines: A textbook for high schools (Energy, 1980).

18. E.G. Kurenniy E.G., E.N. Dmitrieva, A.P. Lyuty, O.A. Sidorenko, Assessment and regulation of voltage unbalance in general-purpose power supply systems, Electrichestvo, No. 4, (2008).

19. GOST 32144-2013. Electrical energy.

Electromagne-tic compatibility of technical equipment. Power quality limits in public power supply systems, (2014).

20. National technical regulation on electrical engineering 2015/BCT - Part 1: Electricity network system (Vietnam, 2015).

21. Vietnam-Hungari electric machinery manufacturing joint stock company. URL: http: www.vihem.com.vn. 